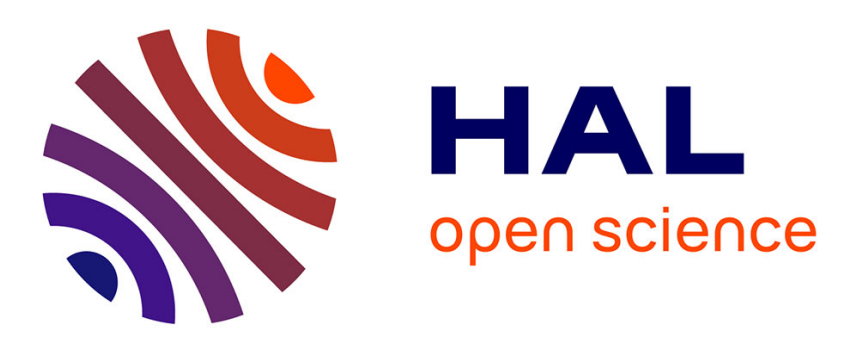

\title{
An optimal energetic approach for systemic design of hybrid powertrain
}

Francis Roy, Florence Ossart, Claude Marchand

\section{To cite this version:}

Francis Roy, Florence Ossart, Claude Marchand. An optimal energetic approach for systemic design of hybrid powertrain. IEEE VPPC 2014, Oct 2014, Coimbra, Portugal. pp.1-6, 10.1109/VPPC.2014.7007014 . hal-01099600

\section{HAL Id: hal-01099600 \\ https://hal-centralesupelec.archives-ouvertes.fr/hal-01099600}

Submitted on 11 Mar 2020

HAL is a multi-disciplinary open access archive for the deposit and dissemination of scientific research documents, whether they are published or not. The documents may come from teaching and research institutions in France or abroad, or from public or private research centers.
L'archive ouverte pluridisciplinaire HAL, est destinée au dépôt et à la diffusion de documents scientifiques de niveau recherche, publiés ou non, émanant des établissements d'enseignement et de recherche français ou étrangers, des laboratoires publics ou privés. 


\section{An optimal energetic approach for systemic design of hybrid powertrain}

\author{
Francis Roy ${ }^{1,2}$ \\ ${ }^{1}$ PSA Peugeot Citroën, \\ La Garenne-Colombes, France \\ e-mail : francis.roy1@,mpsa.com
}

\author{
Florence Ossart ${ }^{2}$, Claude Marchand ${ }^{2}$ \\ ${ }^{2}$ Laboratoire de Génie Electrique de Paris (LGEP) \\ CNRS UMR8507, SUPELEC, UPMC, Univ. Paris-Sud \\ Plateau de Moulon 91192 Gif sur Yvette, France \\ e-mail: florence .ossart@,lgep.supelec.fr, \\ claude.marchand@lgep.supelec.fr
}

\begin{abstract}
On-going oil stock depletion and growing environmental concerns lead automakers to develop more efficient powertrains. Today, the most promising way forward consists in research on hybrid systems. Defining the most efficient powertrain requires a systemic design. In this paper, three main levers are used: powertrain architecture, energy management and electric components design. Different powertrain architectures (series, parallel and combined) are compared: their optimal energetic performances are calculated for different INRETS $^{1}$ driving cycles by using dynamic programming as an optimal control strategy. The most promising hybrid powertrain is the parallel one. Its behavior is more closely analyzed so as to provide technical specifications for an optimal sizing of the electric components: electric machine and battery.
\end{abstract}

Keywords - HEV (Electric Hybrid Vehicle), passenger car, systemic design, power management, energy consumption

\section{INTRODUCTION}

In the current context of increasing demand for personal transportation, on-going oil stock depletion and growing environmental concerns, profound technological mutations are needed to design passenger cars. During the last century, automotive industry has been dominated by internal combustion engine (ICE) based powertrains, despite their rather low efficiency. Improvements in ICE efficiency are still expected, but further enhancements can be achieved by coupling fossil energy source with a complementary on-board one. Nowadays, all automakers are focusing their research and development activities on these hybrid systems to offer more efficient cars with low carbon footprint at affordable prices [1],[2].

Full Hybrid-electric vehicles (HEV) have a classical ICE and at least one electrical machine. The system design aims at taking advantage of both technologies, in order to reach the lowest vehicle fuel consumption. The ICE is fuelled by oil, which has a high energy density and easy on-board storage, while electric machines have high efficiency, zero tank-towheel emissions, and a reversible behavior used for regenerative braking. Fuel is the only energy source (no Plug in function), but the global system efficiency can be improved by proper energy management. A clever balance of the ICE and

${ }^{1}$ INRETS (Institut National de Recherche sur les Transports et leur Sécurité) and LCPC (Laboratoire Central des Ponts et Chaussées) merged in 2011 to create IFSTTAR (Institut Français des Sciences et Technologies des Transports, de l'Aménagement et des Réseaux) the electric machine use allows operating the ICE close to its optimal working point. First control systems were based on heuristic approaches, intuitive and pragmatic, but with limited efficiency. Powerful mathematical methods, such as dynamic programming and Pontryagin principle, are now used for optimal control, the challenge being to go from off-line to online optimal control [3], [4], [5].

Optimal control is also helpful for design purposes: the lowest consumption which can be reached by a given hybrid system can be estimated, and the influence of the design parameters on this optimal consumption analyzed in order to propose an optimal design. This approach has been applied to study different types of hybrid systems: microhybrid HEV [6]; comparison between parallel and power-split HEV [7]; comparison between torque-assist and full-hybrid parallel HEV [8]. More recently, [9] has used convex optimization to design parallel PHEV powertrain. The present study, concerning a HEV B segment vehicle (Peugeot 208), follows the same global systemic approach, but goes further in data analysis to define components specifications in relation with the vehicle use.

The paper is organized as follows. The principle of the model used is presented and optimal control is introduced. Then different HEV powertrain architectures with given components are modeled. Their optimal performances are calculated using optimal energy management and their sensitivity to the electric machine efficiency are compared. The most promising architecture is selected, and its behavior is closely analyzed, so as to define technical specifications for an optimal choice and sizing of the electric components: the smallest battery capacity allowing to reach the optimal consumption is estimated, and the ideal efficiency map of an optimal electric machine is also established.

\section{HYBRID POWERTRAIN MODEL}

\section{A. Powertrain architectures}

In a first step, the three classical hybrid powertrain topologies, depicted on Fig. 1, are considered. The series architecture corresponds to a purely electrical powertrain where the electric power is supplied by an engine-driven generator. The parallel architecture can be seen as an ICE one, assisted by additional electric power. The combined architecture mixes both features. The three architectures need a battery for temporary storage of the energy. 


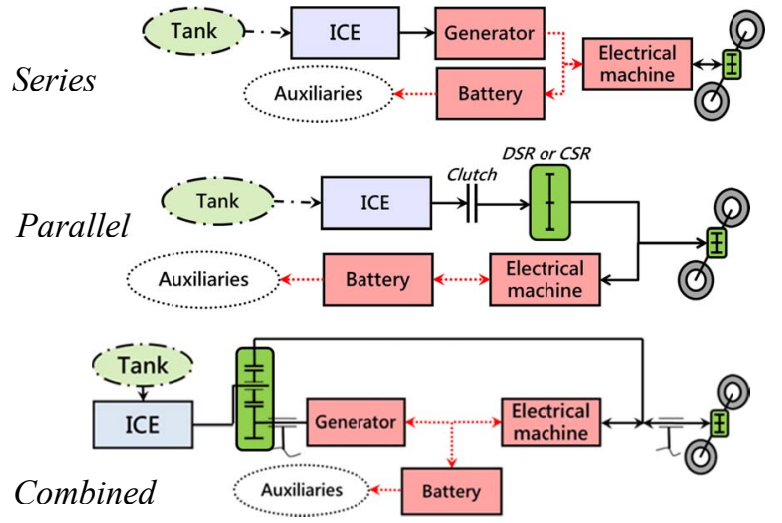

Fig. 1. Series (top), parallel (middle) and combined (bottom) hybrid powertrain architectures - Black solid lines and red dashed ones respectively represent mechanical and electric power flux.

For the architecture performance comparison, the same power components are used in the different architectures. The ICE is a 1.0-liter 3-cylinder in-line gasoline motor and the electrical machines are $50 \mathrm{~kW}$ synchronous motors. Both types of motors are modeled by their efficiency maps.

The parallel architecture has been studied with two different mechanical transmission systems between the ICE and the wheels. The discrete speed ratio system (DSR) corresponds to a classical gear box, with 5 fixed speed ratios, whereas the continuous speed ratio system (CSR) corresponds to an ideal one, with an infinite number of speed ratio. A $97 \%$ efficiency is assumed for both systems. For the combined hybridization, the mechanical transmission corresponds to a planetary gear, which uses an electrical generator to produce a continuous speed ratio.

\section{B. Powertrain model}

The different powertrains have been modeled using a classic backward energetic approach: for a given driving cycle $\omega_{\text {wheel }}(t)$, the wheel power $P_{\text {wheel }}(t)$ is calculated, accounting for dynamic, air and road resistance. At each step of time, the power provided to the wheel is split into power coming from the ICE and power coming from the battery. This results in different operating modes: full electric, boost, recharging battery, braking.

For a given value of the ICE power, the speed $\omega_{I C E}$ and torque $T_{I C E}$ are calculated so as to operate the ICE at its best efficiency for the considered powertrain. The instantaneous fuel consumption $L\left(P_{I C E}\right)$ is then defined by equation (1),

$$
L\left(P_{I C E}\right)=\min _{\omega_{I C E}} \frac{P_{I C E}}{\eta_{I C E}\left(\omega_{I C E}, T_{I C E}\right)}
$$

where $T_{I C E}=\frac{P_{I C E}}{\omega_{I C E}}$ and $\eta_{I C E}\left(\omega_{I C E}, T_{I C E}\right)$ is provided by the ICE efficiency map.

$P_{I C E}, \omega_{I C E}$ and $\omega_{\text {wheel }}$ being known, the following quantities are calculated in turn : working point and electric power of the electric machine using its efficiency map, battery power $P_{b a t t}$ and battery current $I_{\text {batt }}$.
The battery is modeled by its open circuit voltage and internal resistance, and its state of charge $S O C$ is calculated by integrating equation (2):

$$
\operatorname{SOC}(t)=-\frac{I_{\text {batt }}\left(P_{\text {batt }}\left[x(t), P_{I C E}(t)\right], x(t)\right)}{Q_{0}}
$$

where $Q_{0}$ is the nominal capacity of the battery.

\section{Optimal energy management}

The role of the energy management system is to determine the best power split between the electric and thermal energies in order to reach the lowest fuel consumption for a given driving cycle. In the present paper, the ICE power and the battery SOC are taken respectively as control and state variables, denoted $u$ and $x$. With these notations, the total fuel consumption $J$ over a cycle defined on the time interval $I=\left[t_{0}, t_{f}\right]$ is given by equation (4) and the evolution of the system is ruled by equation (5), where $f$ is a function modeling the powertrain.

$$
\begin{aligned}
& J(u)=\int_{t_{0}}^{t_{f}} L(u(t)) d t \\
& \dot{x}(t)=f(x(t), u(t))
\end{aligned}
$$

In order to be meaningful, this consumption must be calculated for identical initial and final energetic states of the system, i.e. for equal initial and final values of the state of charge $x$. Furthermore, the battery SOC range is limited.

The optimal control is defined by the optimization problem (5): find $u$ in the space of possible control functions $U$, so that the total consumption $J(u)$ over a given driving cycle is minimum, and that the constraints on the battery state of charge are fulfilled.

$$
\left\{\begin{array}{c}
u^{*}=\operatorname{argmin}_{u \in U} J[u] \\
\forall t \in I \quad \dot{x}(t)=f[x(t), u(t)] \\
\\
x_{\min } \leq x(t) \leq x_{\max } \\
x\left(t_{0}\right)=x\left(t_{f}\right)
\end{array}\right.
$$

Two approaches are widely used to solve this problem [10]. The first one, proposed by Pontryagin and based on variation calculus, uses the Hamiltonian of the optimal problem (5), denoted $\mathcal{H}$. If the constraint $x_{\text {min }} \leq x(t) \leq x_{\text {max }}$ is relaxed, the Hamiltonian is defined by equation (6):

$$
\begin{array}{r}
\mathcal{H}[x(t), u(t), \lambda(t)] \\
=L(u(t))+\lambda(t) . f(x(t), u(t))
\end{array}
$$

where $\lambda(t)$ is the co-state corfficient associated to equation (4). It represents the unitary cost of the electric power use. Pontryagin principle states that if the control $u^{*}$ is solution of the optimal problem (5), there exists a function $\lambda^{*}(t)$, solution of the differential equation (7):

$$
\dot{\lambda}(t)=-\frac{\partial \mathcal{H}}{\partial x}(x(t), u(t), \lambda(t))
$$

and such that :

$$
\forall t \quad u^{*}(t)=\underset{u(t)}{\operatorname{argmin}} \mathcal{H}\left(x(t), u(t), \lambda^{*}(t)\right)
$$


In the case of full HEV, the influence of the state of charge on the parameters of the battery (open circuit voltage and internal resistance) can be neglected. Equation (7) becomes $\dot{\lambda}(t)=0$, and $\lambda$ is constant during the driving cycle. The problem becomes :

$$
\left\{\begin{array}{c}
\text { Find } \lambda^{*} \text { such that } \\
\forall t \in I \quad u^{*}(t)=\underset{u(t)}{\operatorname{argmin}} L(u(t))+\lambda^{*} . f(u(t)) \\
x\left(t_{0}\right)=x\left(t_{f}\right)
\end{array}\right.
$$

The problem is easily solved by applying a simple dichotomic algorithm to satisfy $x\left(t_{0}\right)=x\left(t_{f}\right)$.

The second principle is dynamic programming, introduced by Bellman [12]. The global optimal problem is solved by breaking down the problem into sub problems easier to solve by using Hamilton-Jacobi-Bellman equation.

The problem is discretized in time, with $t_{k}=t_{0}+$ $(\mathrm{k}-1) . \Delta \mathrm{t}, 0 \leq k \leq N$ and $t_{N}=t_{f}$. Equations (3) and (4) become:

$$
\begin{gathered}
J(u)=\sum_{k=0}^{N-1} L_{k}\left(u_{k}\right) \\
x_{k+1}=x_{k}+f_{k}\left(x_{k}, u_{k}\right)
\end{gathered}
$$

$u_{k}$ and $x_{k}$ denote the control and state variable at time $t_{k}$. $L_{k}\left(u_{k}\right)$ and $f_{k}\left(x_{k}, u_{k}\right)$ are respectively the cumulated fuel consumption and battery state of charge evolution over the time interval $\left[t_{k}, t_{k+1}\right]$.

For a given final state $x_{f}$, the cost-to-go function $V_{k}\left(x_{k}\right)$ is introduced and defined as the minimum fuel consumption to go from a given state $x_{k}$ at time $t_{k}$ to the final one $x_{N}=x_{f}$. This function is calculated by a backward procedure starting from the final state. At each step of time, equation (11) is solved.

$$
\begin{aligned}
V_{k}\left(x_{k}\right)=\min _{u_{k}}\{ & L_{k}\left(u_{k}\right) \\
& \left.+V_{k+1}\left(x_{k}+f_{k}\left(x_{k}, u_{k}\right)\right)\right\} .
\end{aligned}
$$

At the final step of the process, the following results are available: minimum fuel consumption over the cycle (equal to $V_{0}\left(x_{0}\right)$ ), optimal sequence of commands $\left[u_{k}{ }^{*}\right]_{k=0, N-1}$ and optimal SOC trajectory $\left[x_{k}{ }^{*}\right]_{k=0, N-1}$.

For this study, both methods have been implemented. Pontryagin principle leads to easy implementation and fast calculations in the simplified case where the constraint $x_{\min } \leq x(t) \leq x_{\max }$ is left out. Including this constraint is possible, but the simplicity of the algorithm is lost. On the other hand, dynamic programming is more complex, but constraints on the SOC are easily implemented. The computation time is longer than for Pontryagin algorithm: about 10 seconds instead of $0.1 \mathrm{~s}$ for a given cycle, but this is not an issue in the context of this work and dynamic programming has been preferred for the sake of generality. However, it can be noted that both methods are linked: [13] demonstrate that the unitary cost $\lambda$ and the cost-to-go function respect formula (12). This property will be used to calculate $\lambda$ in the context of dynamic programming.

$$
\forall k \quad \lambda_{k}=\frac{\partial V_{k}}{\partial x}\left(x_{k}^{*}\right)
$$

\section{ARCHITECTURE COMPARISON}

The three architectures presented on Fig.1 have been simulated for different INRETS driving cycles [14], using dynamic programming. The optimal control function $u^{*}(t)$ and all the resulting quantities were calculated: electric power, intensity and state of charge of the battery, and finally total fuel consumption.

\section{A. Unitary cost}

The unitary cost $\lambda(t)$ of the electric power was calculated using formula (12). As expected according to the assumptions, a constant value is found. This constant value is plotted as a function of the vehicle mean speed on Fig. 2. In the case of series and combined hybridization, the dependence of $\lambda$ on the cycle and mean speed is very small, whereas a very different behavior is observed for parallel hybridization, with a strong increase for urban cycles. In this situation, parallel hybridization requires electric branch use at low ICE efficiency.

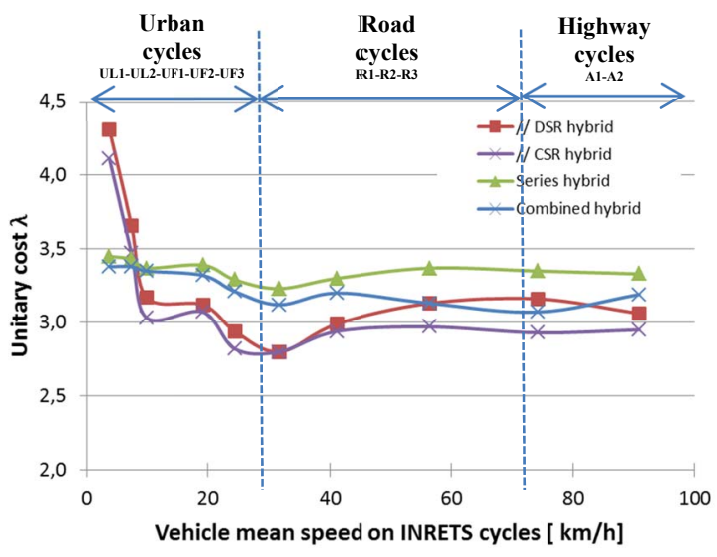

Fig. 2. Unitary cost $\lambda$ of the series, parallel and combined powertrains for different INRETS driving cycles

\section{B. $\mathrm{CO}_{2}$ saving}

For each cycle, the fuel consumption is converted into $\mathrm{CO}_{2}$ saving compared to a conventional ICE vehicle with a classical DSR gearbox (reference system). Fig. 3 presents the result as a function of the vehicle mean speed over the considered driving cycle.

All hybridization topologies show the same trend: the lowest the speed, the highest the $\mathrm{CO}_{2}$ saving. From a strict energetic point of view, the series architecture is the less effective one, victim of the successive energy conversions (mechanical and electrical). The combined hybridization, using a planetary gear, is slightly more performing, but its efficiency is limited by the losses in the electrical device used to produce the desired continuous speed ratio. 


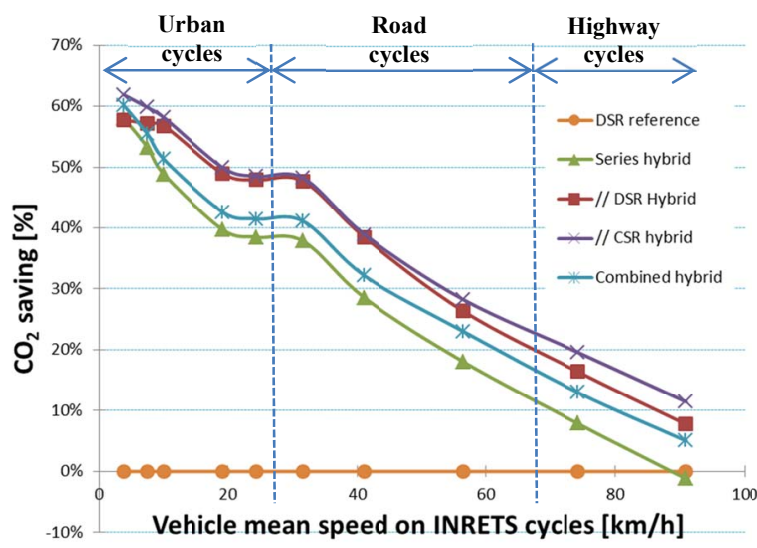

Fig. 3. $\mathrm{CO}_{2}$ saving performances of the series, parallel and combined powertrains, for different INRETS driving cycles

The parallel architecture appears to be the most interesting one, especially if equipped with an ideal CSR system $(97 \%$ efficiency). Such high efficiency CSR systems are not available at the time being, but this simulation result gives an estimate of the best performance that could be reached, and can be used to optimize the speed ratio of a classical DSR gearbox. A remarkable point is that for urban cycles with congested traffic (very low mean speed), all hybridizations topologies seem to converge towards the same level of $\mathrm{CO}_{2}$ saving.

\section{Influence of the electrical machine efficiency}

The previous comparison is a first indication of the interest of the parallel architecture, but one may object that the components of each architecture should be optimized before drawing any conclusion. In order to have a significant criterion before undergoing such optimization, the influence of the electric machine efficiency is examined.

Fig. 4 shows the $\mathrm{CO}_{2}$ saving calculated for the three architectures, assuming a constant efficiency of the electric machine. A first set of curves (dashed lines) corresponds to an ideal electric machine $(100 \%$ efficiency). The small discrepancies between the different powertrain are due to mechanical and battery losses only, and the parallel architecture performs slightly better. A second set of curves (full lines) is calculated, assuming the electric machine efficiency is $80 \%$.

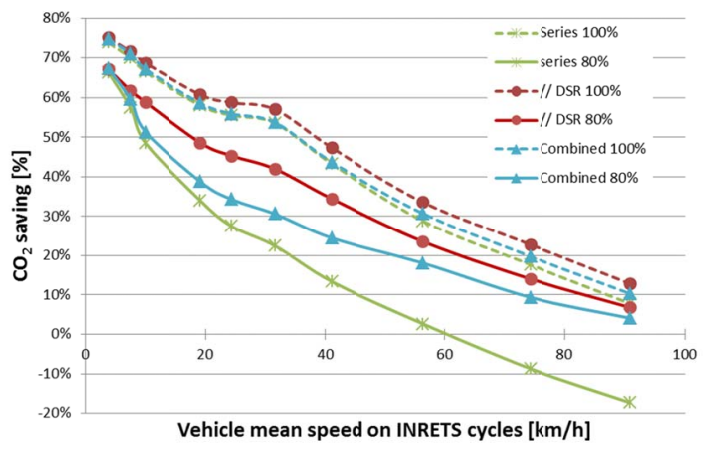

Fig. 4. Influence of electric machine efficiency on $\mathrm{CO}_{2}$ saving for series, parallel and combined hybridization on different INRETS driving cycles
The results clearly show that the parallel architecture is less sensitive to the electric machine efficiency. This can be explained by the fact that the series and combined architecture constantly use electric power. This result is very important, because it shows that the parallel architecture does not require a high efficiency electric machine to perform well. Hence it should allow an interesting trade-off between $\mathrm{CO}_{2}$ saving and electric machine cost.

\section{Influence of the gearbox position}

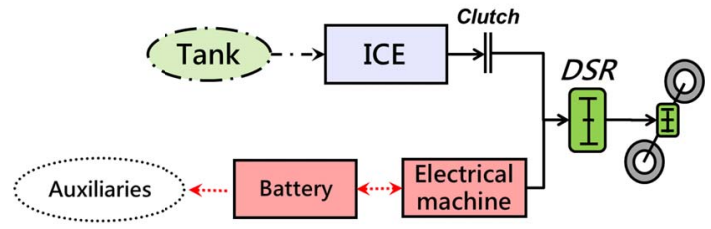

Fig. 5. Improved parallel powertrain architecture

The parallel powertrain architecture can be improved by coupling the electric and the thermal branches upstream the DSR gearbox (Fig. 5). This allows to optimize the operating points of the electric machine during pure electric driving (ZEV mode). Fig. 6 shows that the position of the gearbox improves the consumption for slow urban cycles, where ZEV mode is the most activated one.

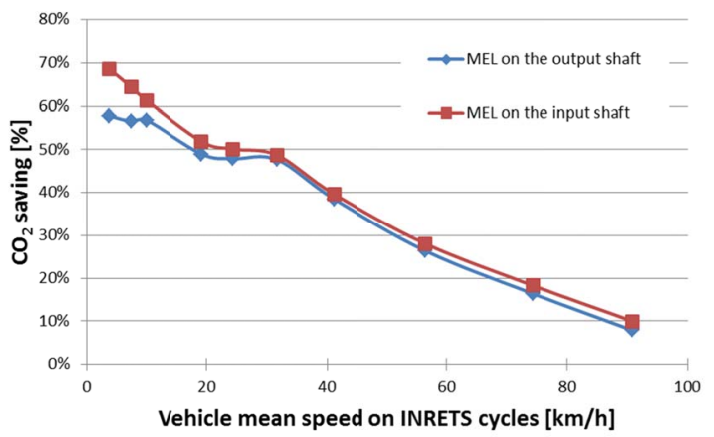

Fig. 6. $\mathrm{CO}_{2}$ saving due to electric machine location, coupling on the input shaft / output shaft of the gearbox.

\section{ELECTRIC COMPONENT SPECIFICATIONS}

The study now focuses on the parallel architecture presented in Fig. 5, in order to establish technical specifications for the optimal design of the electric machine and the battery.

\section{A. Regenerative braking contribution to $\mathrm{CO}_{2}$ saving}

The components design should be guided by a good understanding of their load. Fig. 7 analyzes the contribution of the mechanisms permitting fuel consumption gains. For slow urban cycle, $\mathrm{CO}_{2}$ saving is due to optimization of the ICE working point, whereas at higher mean speed it is due to regenerative braking. For highway cycles, the EM efficiency has a lower effect on the vehicle consumption because of little use of the electric machine. These observations can be used when designing the electric machine, as will be discussed in paragraph IV.C. 


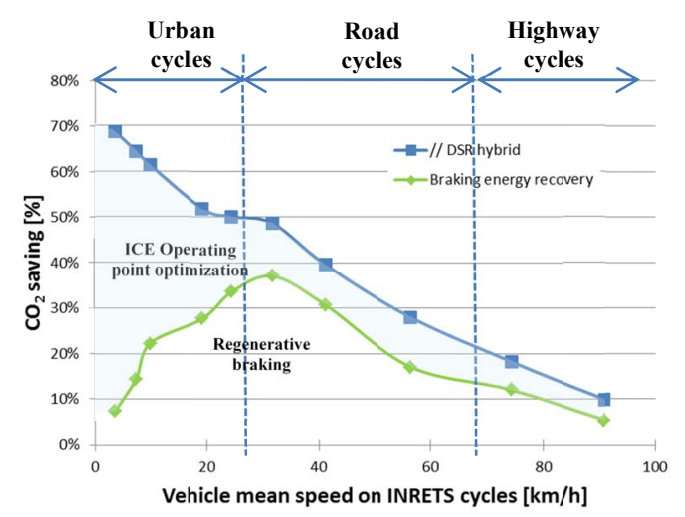

Fig. 7. Analyzis of $\mathrm{CO}_{2}$ saving for the parallel DSR hybrid powertrain: the green curve shows the part of $\mathrm{CO}_{2}$ saving due to braking energy recovery, and the blue area corresponds to the amount of saving due to the ICE working point optimization.

\section{B. Electric machine power}

The previous simulations were performed for a $50 \mathrm{~kW}$ electric machine as a starting point. This choice allows a pure electric mode at any wheel power, but leads to an oversized machine if one considers potential consumption gains. The influence of the electric machine power has been calculated by using an efficiency map scaled with respect to the torque. Some of the results (urban fluid cycles UF1/UF2 and road cycles R1/R2) are plotted on Fig. 8. It shows that a $25 \mathrm{~kW}$ electric machine is powerful enough to minimize $\mathrm{CO}_{2}$ emissions. This power requirement mainly depends on regenerative braking mode and can be reconsidered to a lower level if taking into account the braking distribution between the front and rear axle gears needed to provide vehicle stability. Other design constraints must be also considered, like the performances required for the ZEV mode.

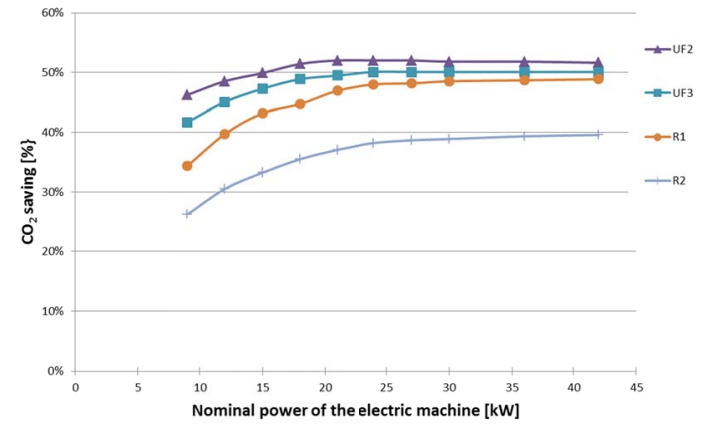

Fig. 8. $\mathrm{CO}_{2}$ saving versus nominal electric machine power for different INRETS cycles (UF2, UF3, R1 and R2)

\section{Electric machine efficiency map}

As introduced in paragraph IV.A, consumption gains are due to two phenomena: ICE working point optimization, which dominates for slow urban cycles, and regenerative braking, which dominates for road cycles. This may lead to different specifications when designing the electrical machine. For this reason, it is interesting to detail the electric machine load. Fig. 9 represents the energy distribution in the torques-speed plane of the machine, for given driving cycles. The red part of the plane corresponds to the working points which are the most used during the cycles (high percentage of the total energy is converted at these operating points). On the contrary, blue parts corresponds to working points through which little energy transits. This map shows the region of the plane where the efficiency should be improved.

Fig. 9.a. and 9.b analyze the electric machine load respectively for urban cycles UL1/.../UF2 and road cycle R1. These two pictures can be interpreted as ideal electric machine efficiency map and give the technical requirements to select the best electric machine architecture (synchronous permanent magnet, asynchronous ...) and improve its design.
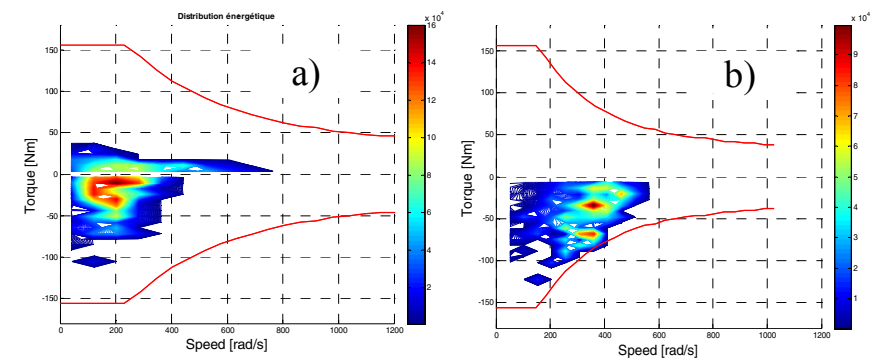

Fig. 9. Energy distribution of the electric machine load in traction mode (a) on INRETS Urban cycles and in generator mode (b) for a road cycle (INRETS R1).

\section{Battery specifications}

This paragraph deals with the battery sizing: its power should be chosen according to the electric machine power, and the next analysis focuses on its capacity, which must be adapted to the energy transfers actually needed.

To study the influence of the battery capacity on $\mathrm{CO}_{2}$ saving, one needs to take into account the SOC limitation in the simulation, and the fact that it may not be possible to store all braking energy if the battery capacity is too small. These constraints are easily included in dynamic programming.
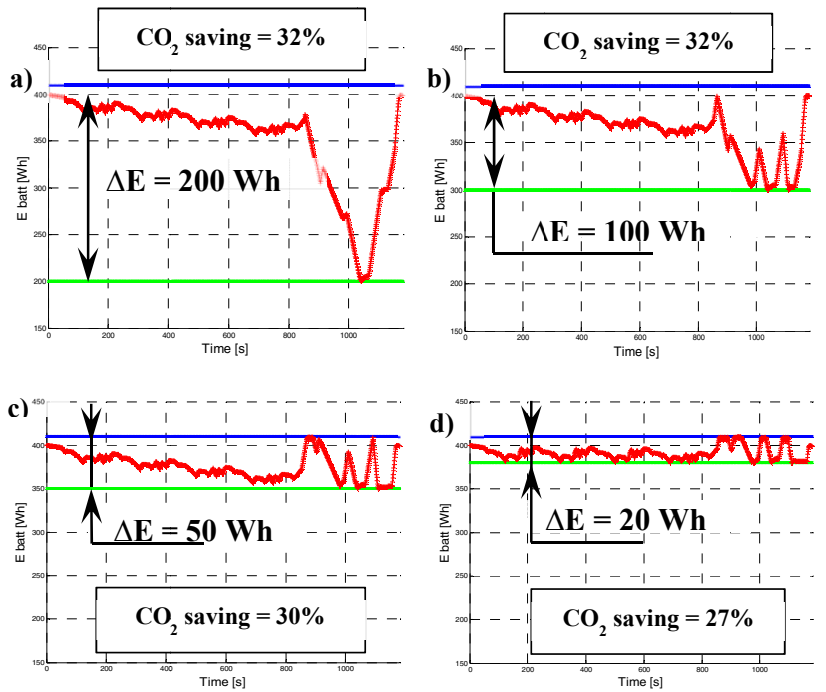

Fig. 10. Battery energy versus time (red line) for // DSR hybridization with different SOC limitations on a NEDC driving cycle - The blue and green lines respectively correspond to the highest and lowest level energy in the battery 
Fig. 10 shows the evolution of the energy stored in the battery during a NEDC cycle (red line) for different battery capacities: $200 \mathrm{Wh}, 100 \mathrm{Wh}, 50 \mathrm{Wh}, 20 \mathrm{Wh}$. A decreasing energy means that the battery is providing electrical energy to the wheels, whereas an increasing energy means that the battery is recharged either by the wheels or the ICE. The influence of the battery limits is clearly seen on the trajectory and on the consumption. For battery capacities larger than 100 Wh (Fig. 10.a and 10.b), the vehicle consumption is not affected, but for battery capacities below (Fig. 10.c and 10.d), the vehicle consumption increases as the battery capacity is too small to permit full recovery of the braking energy. This analysis enables to define the optimal battery capacity for the considered cycle: about $100 \mathrm{Wh}$ for a NEDC cycle. This value can be correlated to the amount of kinetic energy to be recovered at the end of the NEDC cycle (Fig. 11).

This analysis has been done for all the INRETS cycles, and the smallest battery capacity needed to achieve the optimal consumption for each cycle is plotted on Fig. 12. A capacity of $60 \mathrm{Wh}$ appears to be a good choice.

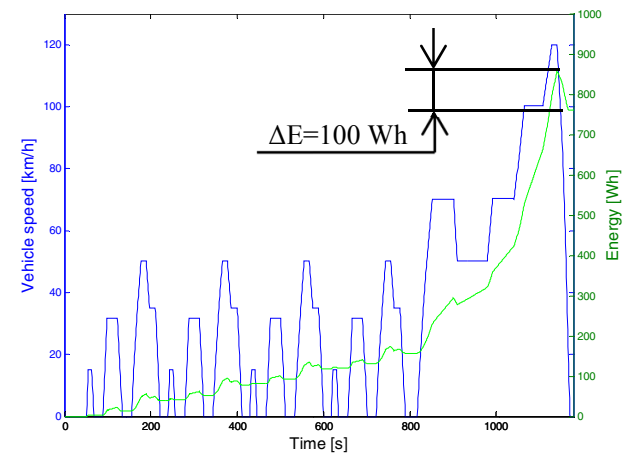

Fig. 11. Power at the wheel (blue line) and cumulated energy (green line) versus time for the NEDC cycle

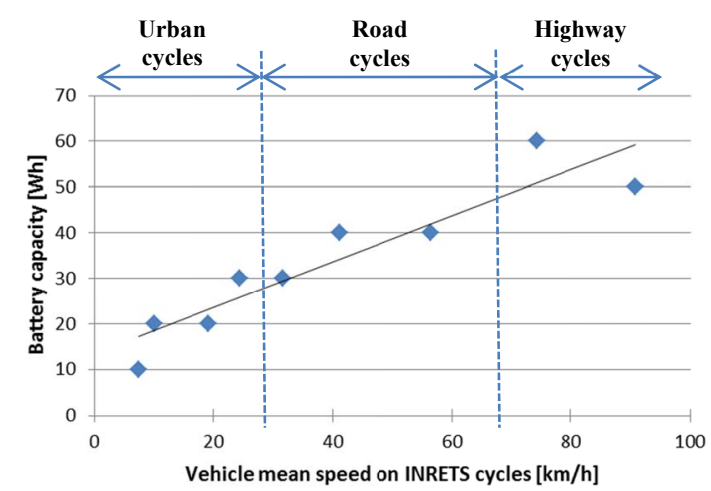

Fig. 12. Smallest battery capacity needed to achieve the lowest vehicle consumption for the differents INRETS driving cycles.

\section{CONCLUSION}

The present work uses dynamic programming as a powerful tool to calculate the minimum global consumption of a given hybrid powertrain. A comparative study of different architectures for various driving cycles was undertaken. From a strict energetic point of view, the series architecture does not bring much benefit to electric hybrid vehicle. The combined hybridization is slightly more performing, but very sensitive to electric machine efficiency. The parallel architecture appears to be the most promising one.

In a second part, the study focuses on electric power components design to optimize the powertrain efficiency for parallel hybridization. It is shown how the battery capacity can be sized to optimize regenerative braking.

Guidelines are given for the electric machine design. They point out the need of optimizing the ICE working points for low urban cycles on one hand and braking energy recovery for urban fluent and road cycles on the other hand.

The next step is to design an electric machine according to these specifications and to develop an on-line optimal control for prototype implementation.

\section{REFERENCES}

[1] «New Hybrid Reviews, News \& Hybrid Mileage (MPG) Info | Hybrid Cars » . [On line]. Available: http://www.hybridcars.com.

[2] L. Guzzella, A. Sciarretta, Vehicle Propulsion Systems: Introduction to Modeling and Optimization, Berlin, Germany: Springer-Verlag, 2007.

[3] S. Delprat, J. Lauber, T. M. Guerra, and J. Rimaux, "Control of a Parallel Hybrid Powertrain: Optimal Control», IEEE Trans. Veh. Technol., vol. 53, no 3, pp. 872-881, May 2004.

[4] A. Sciarretta et L. Guzzella, « Control of hybrid electric vehicles », Control systems, IEEE, vol. 27, no 2, pp. 60-70, 2007.

[5] N. Kim, S. Cha, and H. Peng, «Optimal Control of Hybrid Electric Vehicles Based on Pontryagin's Minimum Principle », IEEE Transactions on Control Systems Technology, vol. 19, no 5, pp. 1279-1287, Sept. 2011.

[6] G. Rousseau, D. Sinoquet, et P. Rouchon, « Constrained Optimization of Energy Management for a Mild-Hybrid Vehicle», Oil Gas Sci. Technol., vol. 62, no 4, pp. 623-634, July 2007.

[7] E. Vinot, R. Trigui, B. Jeanneret, J. Scordia, and F. Badin, «HEVs comparison and components sizing using dynamic programming », in Proc. IEEE Vehicle Power Propulsion Conf., Arlington, TX, 2007, pp. 314-321.

[8] O. Sundström, L. Guzzella, and P. Soltic, « Optimal hybridization in two parallel hybrid electric vehicles using dynamic programming », in Proc. 17th IFAC World Congr., Seoul, Korea, 2008, pp. 4642-4647.

[9] M. Pourabdollah, N. Murgovski, A. Grauers, and B. Egardt, « Optimal Sizing of a Parallel PHEV Powertrain », IEEE Trans. Veh. Technol., vol. 62, no 6, pp. 2469-2480, July 2013.

[10] D.E. Kirk, Optimal control theory: an introduction, Mineola NY: Dover publications, 2004.

[11] L.S Pontryagin, V.G Boltyanskii, R.V. Gamkrelidze, and E.F Mishchenko, The mathematical theory of optimal processes, New York: Interscience Publishers, Inc., 1962.

[12] R.E Bellman, Dynamic programming, Princeton, NJ: Princeton Univ. Press, 1957.

[13] F.H. Clarke, and R.B. Vinter, "The Relationship between the Maximum Principle and Dynamic Programming", SIAM J. Control and Optimization, vol. 25, no 5, pp. 1291-1311, Sept. 1987.

[14] R. Joumard, M. André, R. Vidon, P. Tassel, and C. Pruvost, "Influence du cycle de conduite sur les émissions unitaires de polluants des voitures particulières", Rapport n LTE 9902,Dec. 1999. [On line]. Available : http://www.inrets.fr/ur/lte/publications/publipollu.html\#pollurap 